\title{
Phosphorus Metabolites and Intracellular pH in the Brains of Normal and Small for Gestational Age Infants Investigated by Magnetic Resonance Spectroscopy
}

\author{
D. AZZOPARDI, J. S. WYATT, P. A. HAMILTON, E. B. CADY, D. T. DELPY, P. L. HOPE, \\ E. O. R. REYNOLDS \\ Departments of Paediatrics [D.A., J.S.W., P.A.H., P.L.H., E.O.R.R.], and Medical Physics and Bioengineering \\ [E.B.C., D.T.D.], University College and Middlesex School of Medicine, London, England
}

\begin{abstract}
The brains of 30 normal preterm and term infants whose birth wt were appropriate for gestational age and 13 who were small for gestational age but healthy were studied by phosphorus magnetic resonance spectroscopy to determine values for metabolite concentration ratios and intracellular pH. In the AGA infants, phosphocreatine/ inorganic orthophosphate increased between 28 and 42 wk of gestational plus postnatal age, suggesting a rise in the phosphorylation potential of brain tissue. At the same time, the concentration of phosphomonoester (mainly phosphoethanolamine) fell and that of phosphodiester (including phosphatidylethanolamine and phosphatidylcholine) increased. These changes reflected myelination and proliferation of membranes. Intracellular $\mathrm{pH}$ was $\sim 7.1$ and did not change with brain maturation. No differences were detected in these variables between the infants who were small for gestational age and those who were appropriate for gestational age. (Pediatr Res 25:440-444, 1989)
\end{abstract}

\section{Abbreviations}

AGA, appropriate for gestational age

SGA, small for gestational age

${ }^{31} \mathrm{P}$ MRS, phosphorus magnetic resonance spectroscopy

$\mathrm{PCr}$, phosphocreatine

$\mathrm{Pi}$, inorganic orthophosphate

PME, phosphomonoester

PDE, phosphodiester

total $\mathbf{P}$, total mobile phosphorus

$\mathrm{pH}_{\mathrm{i}}$, intracellular $\mathrm{pH}$

It has previously been shown that the relative concentrations of mobile phosphorus compounds involved in energy metabolism, and in cell synthesis and myelination, can be measured noninvasively in the brain tissue of newborn infants by ${ }^{31} \mathrm{P}$ MRS $(1,2) \cdot \mathrm{pH}_{\mathrm{i}}$ can also be estimated. Obvious abnormalities of phosphorus metabolites and $\mathrm{pH}_{\mathrm{i}}$ have been found in a wide variety of conditions involving hypoxic-ischemic brain injury, including birth asphyxia, periventricular leukomalacia and other

Received September 13, 1988; Accepted December 8, 1988.

Address for correspondence and reprint requests Prof E. O. R. Reynolds, Department of Paediatrics, UCMSM. The Rayne Institute, 5, University Street, London, WC1E 6JJ, England.

Supported by the DHSS, MRC, Wellcome Trust, and Action Research for the Crippled Child. forms of cerebral infarction, and periventricular hemorrhage (36). So far, only very small numbers of infants with apparently normal brains have been studied $(3,5,7)$, and no information has been obtained about whether any systematic differences exist between infants whose birth wt are AGA and infants who are SGA.

The purposes of the present investigation were to establish normal values for AGA infants, to find out if maturational changes occurred, and to see if any differences could be demonstrated between SGA and AGA infants.

\section{MATERIALS AND METHODS}

Infants studied. Forty-three infants were studied. They were born at 24-42 (mean 33) wk of gestation and weighed 562-3860 (mean 1814) g at birth. Of these infants, 28 were boys and 15 , girls; 38 were born in University College Hospital, and 5 were referred from other hospitals. None had any evidence of birth asphyxia or significant illness. Gestational age was assigned from maternal dates, antenatal ultrasound scans, and the physical and neurologic characteristics of the infants (8). Of the infants, 30 ( 21 boys, 9 girls) were AGA with birth wt between the 10th and 90th (mean 60th) percentiles; and 13 were SGA with birth wt below the 3rd percentile (9). None of the latter infants had any notable antenatal or postnatal problems and hence provide data for an "unstressed" SGA group. Their head circumferences were generally in proportion to their other measurements: 11 had head circumferences below the 3 rd percentile, and the other two, on the 3 rd and 25th centiles (9). None of the AGA or SGA infants had any abnormal neurologic signs. Ultrasound scans of the brain, performed as previously described with a Diasonics Sonotron (Bedford, England) DS1 sector scanner with 6- and 7.5-MHz probes (10) were also normal, except in one AGA infant born at $28 \mathrm{wk}$ of gestation in whom a possible small germinal layer hemorrhage was seen.

This study was approved by the University College London Committee on the Ethics of Human Experimentation, and informed parental consent was obtained.

MRS. MRS was performed when the infants were 1-96 (median 4) d old. 38 infants were 1-8 d old, and five infants were 13-96 d old. Their gestational plus postnatal ages were 26-42 (median 34) wk. The technical details have been given elsewhere (3-5, 11). Briefly, an Oxford Research Systems (Oxford, England) TMR 32-200 spectrometer operating at a field strength of 1.89 Tesla was used. The infant was transported to the spectrometer within a Perspex cylinder mounted on top of a standard transport incubator. The cylinder was then detached and positioned within the bore of the magnet. 
The infant's head lay on a 5- or 7.4-cm diameter magnetic resonance surface coil which could be tuned to the resonance frequencies of both ${ }^{31} \mathrm{P}(32.5 \mathrm{MHz})$ and protons $(80.3 \mathrm{MHz})$. The coil supplied the exciting radiofrequency pulse and also detected the magnetic resonance signal returning from the sensitive vol of the magnet, which was centered on the infant's adjacent temporoparietal cortex. The pulse duration was $80 \mu \mathrm{s}$ for the $5-\mathrm{cm}$ coil and 90 or $100 \mu \mathrm{s}$ for the $7.4-\mathrm{cm}$ coil. The flip angle at the center of the coil was between $90^{\circ}$ and $100^{\circ} .{ }^{31} \mathrm{P}$ spectra were produced as the sum of 256-768 pulses at intervals of $2.256 \mathrm{~s}$. The accumulated free induction decays were processed by means of $12-\mathrm{Hz}$ exponential line broadening to improve the signal to noise ratio and an enhancement technique to increase resolution and remove the broad spectral feature due to membrane phospholipid, myelin, and phosphorus atoms in bone (12). The magnitude of this broad signal was also measured, after subtraction of the processed spectra. The relative concentrations of the phosphorus metabolites were calculated from the integrals of the gated spectral peaks after applying multiplying factors to correct for the effects of saturation (atomic nuclei not returning fully to their resting state between pulses). These factors were obtained from studies of six infants, born at 30-40 (median 33) wk of gestation, from whom spectra were obtained both at 20.256 $\mathrm{s}$, which allowed full relaxation of the excited nuclei (4) and at $2.256 \mathrm{~s}$. These factors did not appear to change with gestation. Mean values were as follows: PME, 2.28; $\mathrm{Pi}, 1.28$; PDE, 1.25; $\mathrm{PCr}, 1.51$; and $\beta$-ATP, 1.24. $\mathrm{pH}_{\mathrm{i}}$ was estimated from the difference in chemical shift between the $\mathrm{PCr}$ and $\mathrm{Pi}$ resonance, using the formula of Petroff et al. (13).

The infants were fed shortly before the studies; no sedation was needed. Their arterial oxygen and carbon dioxide tensions, blood pressure, and blood glucose concentrations were within accepted normal ranges. During each study, the infant's ECG and breathing were continuously monitored (11).

\section{RESULTS}

$A G A$ infants. Figure 1 shows ${ }^{31} \mathrm{P}$ spectra, before and after processing to remove the broad signal, from an AGA infant studied at $40 \mathrm{wk}$ of gestational plus postnatal age. The seven labeled peaks can be assigned, from left to right, as follows: 1 , PME; $2, \mathrm{Pi} ; 3$, PDE; 4 , PCr; 5, 6, and 7, the $\gamma, \alpha$, and $\beta$ nuclei of nucleotide triphosphates, mainly ATP $(14,15)$. Figure 2 shows the relations of $\mathrm{PCr} / \mathrm{Pi}, \mathrm{PME} /$ total $\mathrm{P}$, and $\mathrm{PDE} /$ total $\mathrm{P}$ to gestational plus postnatal age. Table 1 gives the regression equations, and mean values with $95 \%$ confidence limits for concentration ratios of these and other phosphorus metabolites, and for $\mathrm{pH}_{\mathrm{i}}$.
Highly significant increases of $\mathrm{PCr} / \mathrm{Pi}, \mathrm{PCr} /$ total $\mathrm{P}$, and $\mathrm{PDE} /$ total $\mathrm{P}$ with increasing maturation of the brain were demonstrated, together with a fall in PME/total P. In general, similar changes, though less striking, were found when the metabolite
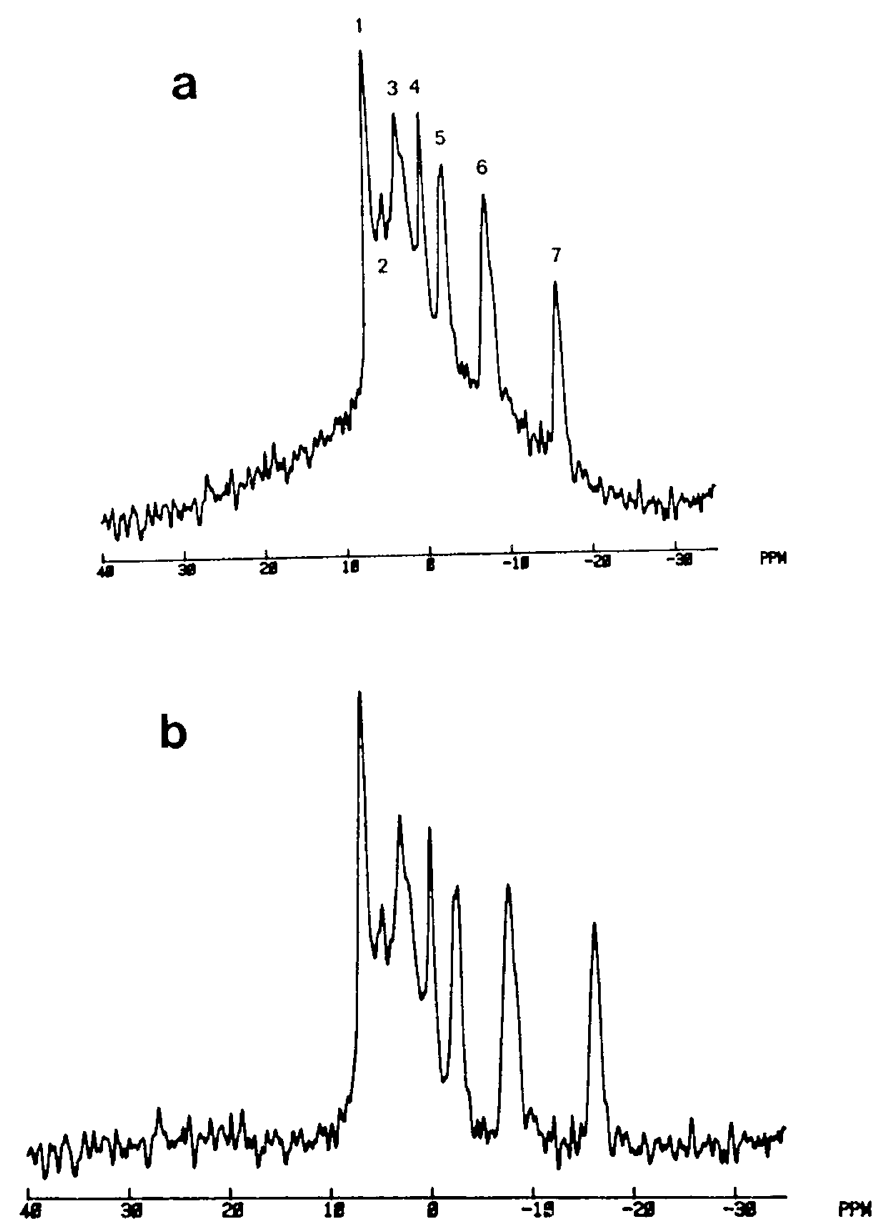

Fig. $1 .{ }^{31} \mathrm{P}$ spectra from an AGA infant studied at $40 \mathrm{wk}$ of gestational plus postnatal age; $a$ is before processing to remove the broad signal and $b$ is afterwards. Peak assignments are given in text. The $y$ axis is signal intensity and the $x$ axis is chemical shift $(\mathrm{ppm})$ relative to the resonance frequency of $\mathrm{PCr}$.
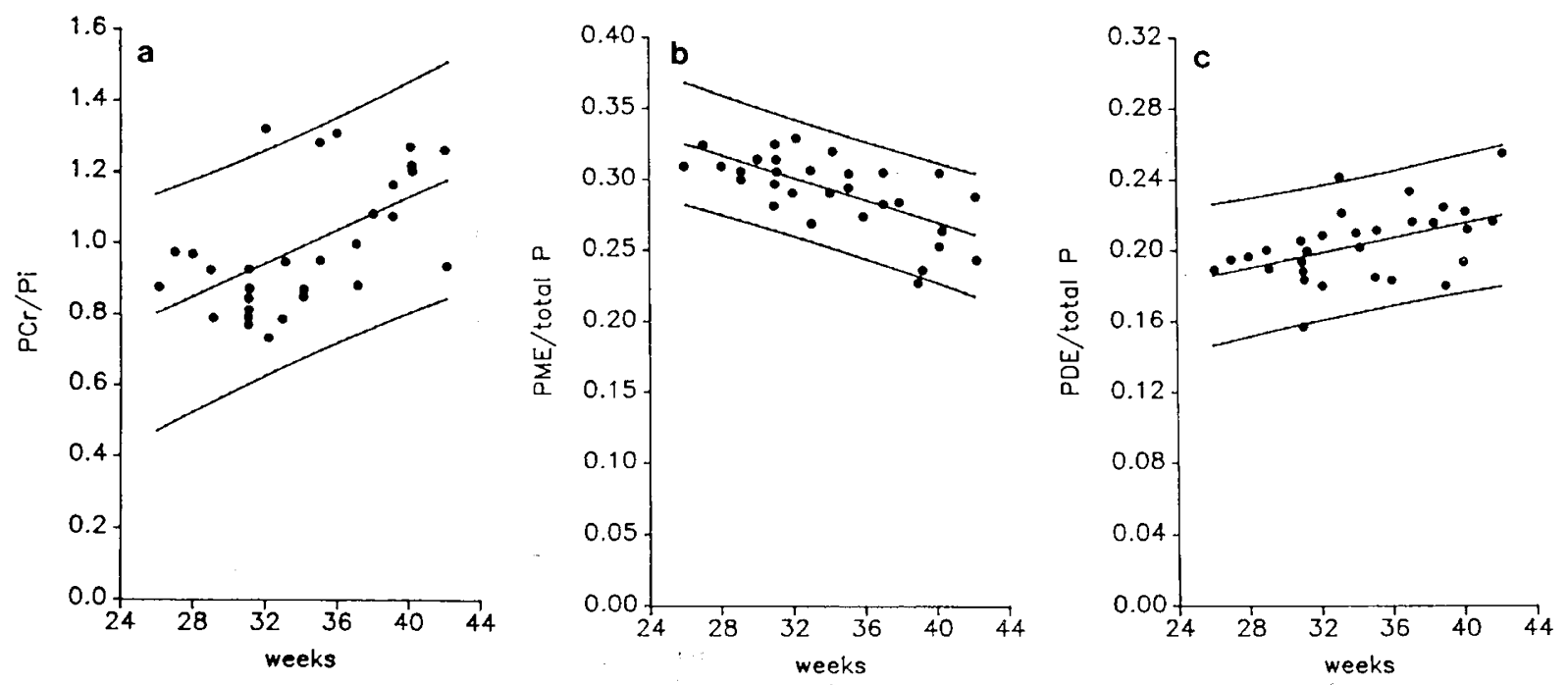

Fig. 2. Relation between metabolite concentration ratios and gestational plus postnatal age in 30 AGA infants. Regression lines and $95 \%$ confidence limits are shown. 
concentrations were expressed relative to ATP, rather than to total $P$. The magnitude of the broad resonance signal underlying the processed spectra (Fig. 1a), when expressed relative to ATP, increased with gestation (Table 1). $\mathrm{pH}_{\mathrm{i}}$ appeared not to change.

$S G A$ infants. Values for $\mathrm{PCr} / \mathrm{Pi}, \mathrm{PME} /$ total $\mathrm{P}$, and $\mathrm{PDE} /$ total $P$ from the 13 infants are compared in Figure 3 with the data from the AGA infants. It can be seen that most of the data points from the SGA infants lie within $95 \%$ confidence limits for the AGA infants. To find out if any significant differences between values from the SGA and AGA infants could be demonstrated, mean standard deviation scores comparing the two groups were calculated. No differences between the data from SGA and AGA infants were found, as demonstrated in Table 2, except for a mean SDS for ATP/total P that just reached statistical significance ( $p<0.05$, Student's $t$ test).

\section{DISCUSSION}

Exact quantitation of the concentrations of phosphorus metabolites in brain tissue by MRS is only just becoming feasible (16), and data for the brains of newborn human infants are not yet available. Because the areas under the spectral peaks (the peak integrals) are proportional to concentration, it is, however, possible to derive concentration ratios, provided appropriate corrections are made, and that is the approach used in this report. Ratios of metabolites are given both with respect to the total concentration of mobile ("MRS-visible") phosphorus metabolites and to the concentration of nucleotide triphosphates, mainly ATP, which appears from chemical analyses to change little with brain maturation (15).

AGA Infants. Energy metabolism. The spectra obtained in this study arose largely from the temporoparietal cortex (17). The striking increase in $\mathrm{PCr} / \mathrm{Pi}$ with increasing maturation of the brain (Fig. 2a) confirms earlier more limited data $(3,5)$. The intracellular pool of $\mathrm{PCr}$ acts, via the creatine kinase reaction, as a buffer to maintain a steady ATP level in the face of increased demands for energy, and it can be shown that $\mathrm{PCr} / \mathrm{Pi}$ is proportional to the phosphorylation potential of the tissue, [ATP]/ [ATP][Pi], (if it is assumed that the concentrations of creatine and hydrogen ions remain constant) (18). The increase in $\mathrm{PCr} /$ $\mathrm{Pi}$ is likely therefore to have been due to an increase in the phosphorylation potential or energy reserve of cortical brain tissue, which undergoes considerable cellular proliferation between $28 \mathrm{wk}$ of gestation and term (19). The parallel rises in $\mathrm{PCr} /$ total P and PCr/ATP are consistent with this view (Table 1).

Data from newborn animals show similar changes with maturation (15). By comparison with these data, the newborn infant seems, in terms of phosphorus energetics, to be at about the same

Table 1. Relation of metabolite concentration ratios and $p H_{i}$ to gestational plus postnatal age in 30 AGA infants*

\begin{tabular}{lcccccc}
\hline & $\mathrm{x}$ & $\mathrm{c}$ & $\mathrm{r}$ & $\mathrm{p}$ & $28 \mathrm{wk}$ & $42 \mathrm{wk}$ \\
\hline $\mathrm{PCr} / \mathrm{Pi}$ & 0.024 & 0.190 & 0.58 & $<0.001$ & $0.85 \pm 0.33$ & $1.18 \pm 0.33$ \\
$\mathrm{ATP} /$ total P & 0.001 & 0.075 & 0.19 & $\mathrm{NS}$ & $0.09 \pm 0.03$ & $0.10 \pm 0.03$ \\
$\mathrm{PCr} /$ total P & 0.001 & 0.051 & 0.56 & $<0.01$ & $0.09 \pm 0.02$ & $0.11 \pm 0.02$ \\
$\mathrm{Pi} /$ total P & -0.001 & 0.128 & -0.40 & $<0.05$ & $0.10 \pm 0.02$ & $0.09 \pm 0.02$ \\
PME/total P & -0.004 & 0.429 & -0.68 & $<0.001$ & $0.32 \pm 0.04$ & $0.26 \pm 0.04$ \\
PDE/total P & 0.002 & 0.131 & 0.47 & $<0.01$ & $0.19 \pm 0.04$ & $0.22 \pm 0.04$ \\
PCr/ATP & 0.009 & 0.717 & 0.20 & $\mathrm{NS}$ & $0.79 \pm 0.42$ & $1.09 \pm 0.42$ \\
Pi/ATP & -0.013 & 1.482 & -0.24 & $\mathrm{NS}$ & $1.13 \pm 0.50$ & $0.95 \pm 0.50$ \\
PME/ATP & -0.050 & 4.887 & -0.37 & $<0.05$ & $3.49 \pm 1.23$ & $2.79 \pm 1.25$ \\
PDE/ATP & 0.016 & 1.658 & 0.15 & $\mathrm{NS}$ & $2.11 \pm 1.03$ & $2.34 \pm 1.05$ \\
Broad resonance/ATP $\dagger$ & 1.011 & -7.790 & 0.49 & $<0.05$ & $20.5 \pm 20.5$ & $34.7 \pm 21.6$ \\
pH & -0.003 & 7.233 & 0.12 & $\mathrm{NS}$ & $7.14 \pm 0.28$ & $7.09 \pm 0.28$ \\
\hline
\end{tabular}

$* \mathrm{x}=$ slope, $\mathrm{c}=$ ordinate intercept, from the regression equations; $p=$ significance of correlation coefficient $r$. Data for $28 \mathrm{wk}$ and $42 \mathrm{wk}$ are mean values $\pm 95 \%$ confidence intervals from the regressions.

$\dagger n=24$.

$\ddagger n=23$ (values for the remaining infants were not calculated, because the spectra were not sufficiently well resolved).
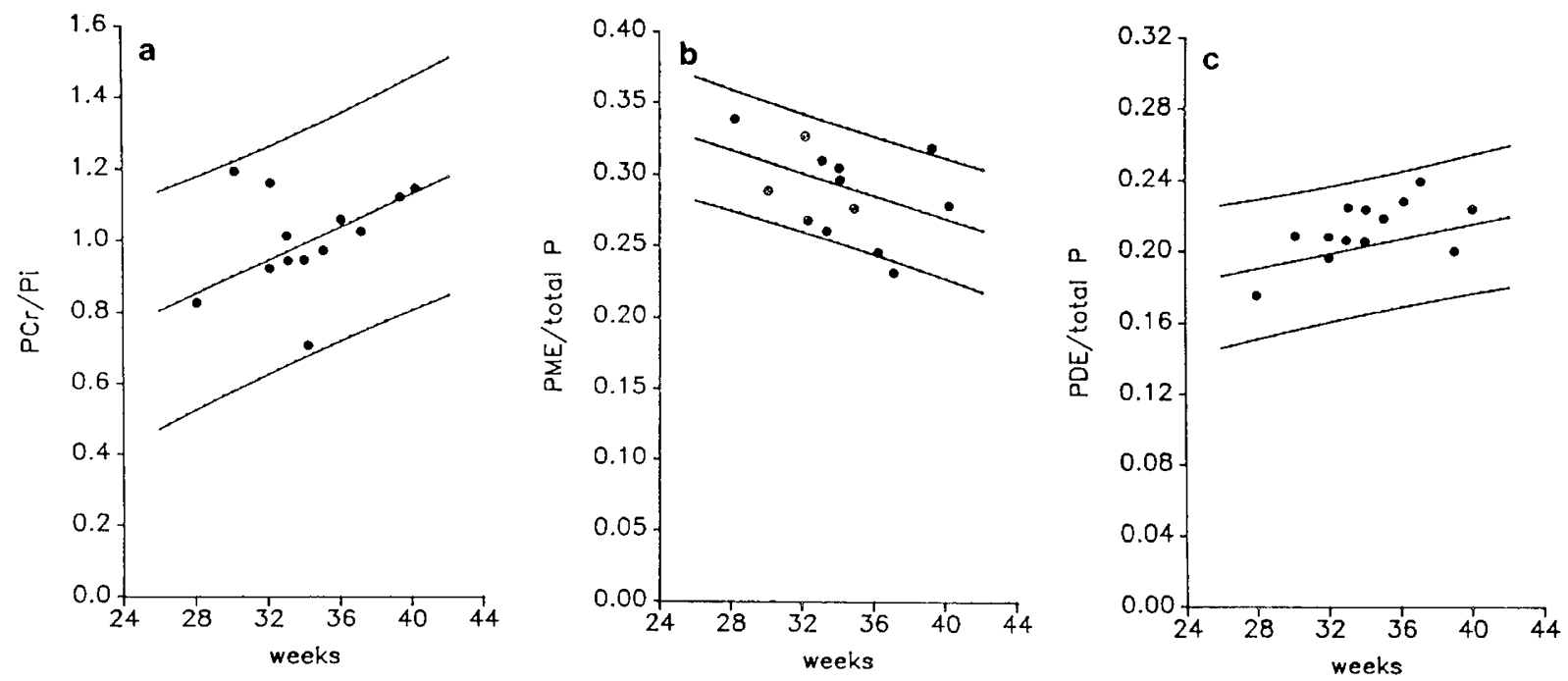

Fig. 3. Relation between metabolite concentration ratios and gestational plus postnatal age in 13 SGA infants. Individual values are shown together with regression lines and $95 \%$ confidence limits for AGA infants (from Fig. 2). 
PHOSPHORUS MRS OF NEONATAL BRAIN

Table 2. Relation of metabolite concentration ratios and $p H_{i}$ to gestational plus postnatal age in 13 SGA infants*

\begin{tabular}{|c|c|c|c|c|c|c|c|}
\hline & $x$ & $\mathrm{c}$ & $r$ & $p$ & $28 \mathrm{wk}$ & $42 \mathrm{wk}$ & SDS \\
\hline $\mathrm{PCr} / \mathrm{Pi}$ & 0.012 & 0.600 & 0.30 & NS & $0.92 \pm 0.38$ & $1.11 \pm 0.38$ & $0.24 \pm 0.82$ \\
\hline $\begin{array}{l}\text { ATP/total P } \\
\mathrm{PCr} / \text { total P } \\
\mathrm{Pi} / \text { total P } \\
\mathrm{PME} / \text { total P } \\
\mathrm{PDE} / \text { total P }\end{array}$ & $\begin{array}{r}-0.001 \\
0.002 \\
0.000 \\
-0.004 \\
0.003\end{array}$ & $\begin{array}{l}0.114 \\
0.041 \\
0.081 \\
0.414 \\
0.116\end{array}$ & $\begin{array}{r}-0.36 \\
0.49 \\
0.16 \\
-0.38 \\
0.57\end{array}$ & $\begin{array}{c}\text { NS } \\
<0.02 \\
\text { NS } \\
\text { NS } \\
<0.01\end{array}$ & $\begin{array}{l}0.09 \pm 0.02 \\
0.09 \pm 0.03 \\
0.09 \pm 0.03 \\
0.31 \pm 0.08 \\
0.20 \pm 0.04\end{array}$ & $\begin{array}{l}0.08 \pm 0.02 \\
0.11 \pm 0.03 \\
0.11 \pm 0.03 \\
0.42 \pm 0.09 \\
0.24 \pm 0.04\end{array}$ & $\begin{array}{r}0.50 \pm 0.5 \dagger \\
0.48 \pm 1.07 \\
-0.01 \pm 1.08 \\
-0.16 \pm 1.44 \\
0.63 \pm 0.76\end{array}$ \\
\hline $\begin{array}{l}\mathrm{PCr} / \mathrm{ATP} \\
\mathrm{Pi} / \mathrm{ATP} \\
\mathrm{PME} / \mathrm{ATP} \\
\mathrm{PDE} / \mathrm{ATP} \\
\text { Broad resonance/ATP }\end{array}$ & $\begin{array}{r}0.028 \\
0.015 \\
-0.013 \\
0.052 \\
1.597\end{array}$ & $\begin{array}{r}0.184 \\
0.624 \\
3.838 \\
0.721 \\
-30.82\end{array}$ & $\begin{array}{r}0.51 \\
0.29 \\
-0.10 \\
0.50 \\
0.58\end{array}$ & $\begin{array}{l}<0.01 \\
\text { NS } \\
\text { NS } \\
<0.01 \\
<0.05\end{array}$ & $\begin{array}{c}0.97 \pm 0.43 \\
1.04 \pm 0.46 \\
3.48 \pm 1.19 \\
2.17 \pm 0.81 \\
14.72 \pm 18.32\end{array}$ & $\begin{array}{c}1.36 \pm 0.46 \\
1.25 \pm 0.50 \\
3.30 \pm 1.27 \\
2.89 \pm 0.86 \\
36.25 \pm 18.33\end{array}$ & $\begin{array}{r}0.50 \pm 0.83 \\
0.28 \pm 0.81 \\
0.28 \pm 0.76 \\
0.56 \pm 0.64 \\
-0.38 \pm 0.99\end{array}$ \\
\hline $\mathrm{pH}_{\mathrm{i}} \ddagger$ & 0.016 & 6.523 & 0.11 & NS & $6.97 \pm 0.24$ & $7.19 \pm 0.24$ & $-0.32 \pm 0.63$ \\
\hline
\end{tabular}

${ }^{*} \mathrm{x}=$ slope, $\mathrm{c}=$ ordinate intercept, from the regression equations; $p=$ significance of correlation coefficient $r$. Data for $28 \mathrm{wk}$ and $42 \mathrm{wk}$ are mean values $\pm 95 \%$ confidence intervals from the regressions. $\mathrm{SDS}=$ standard deviation score $( \pm \mathrm{SD}) v s$. AGA infants.

$\dagger p<0.05$; other values NS.

$\ddagger n=7$.

stage of maturation as the newborn rat, which is an altricious species, but less mature than the guinea pig or lamb, which are precocious $(15,20)$. The greater complexity of the brain at birth in these latter species appears to be associated with a greater energy reserve.

Cell synthesis. The large PME peak has been shown by chemical analysis of the brain in newborn animals to be almost entirely attributable to phosphoethanolamine (21), so it must be assumed that this is also true of the human infant. Phosphoethanolamine is a major precursor of membrane phospholipid and myelin. Clear evidence of a reduction in PME/total P and PME/ATP with maturation of the brain was found (Table 1, Fig. 1b), and it is known that the PME peak is small in spectra from the brains of adult animals and human subjects $(15,22)$. At the same time as the reduction in PME, PDE/total P increased. The PDE peak is due largely to phosphatidylethanolamine and phosphatidylcholine, which are major constituents of membranes and myelin $(21,23)$. The fall in PME and rise in PDE with maturation have also been found in newborn animals (15) and reflect the proliferation of membranes and myelination. The broad resonance signal underlying the spectral peaks is attributable to phosphorus nuclei in bone and also to the phosphate head groups of membrane-bound phospholipids $(21,23-25)$. The signal appears to be reduced in jimpy mice, in which myelination is defective (26). The finding that the broad signal increased in size, relative to ATP, with maturation of the brain is therefore likely to be due both to skull mineralization and to the laying down of increased concentrations of the larger phospholipid components of membranes and myelin.

SGA Infants. SGA infants are known to be at increased risk of neurodevelopmental abnormalities (27). In a previous study, several such infants were found to have evidence of impaired oxidative phosphorylation (low $\mathrm{PCr} / \mathrm{Pi}$ ratios) in brain tissue in association with increased cerebral echodensities (5). To find out whether SGA babies had intrinsic abnormalities of ${ }^{31} \mathrm{P}$ spectra indicating either abnormal energy metabolism or deranged cell synthesis, we therefore selected 13 SGA infants who, apart from being SGA, appeared normal as judged by their clinical features and brain ultrasound scans. No evidence was found of any differences in the phosphorus metabolite ratios or $\mathrm{pH}_{\mathrm{i}}$ between the SGA and AGA infants, except for a borderline reduction in ATP/total P in the SGA infants. There was no evidence from the other metabolite ratios that this apparent reduction indicated impaired oxidative phosphorylation or any other abnormality, and it seems unlikely that it was of biologic significance. Maturational changes in the SGA and AGA infants appeared similar. We believe that derangements of phosphorus spectra indicating impaired oxidative phosphorylation previously found in SGA babies (5) are likely, therefore, to have been due to superimposed perinatal events, rather than any intrinsic cerebral abnormality.

Acknowledgments. The authors are grateful to R. Aldridge, Dr. A. M. de L. Costello, Dr. A. D. Edwards, E. Eldon, Prof. D. R. Wilkie, Dr. Susan Wray, the staff of the Neonatal Unit, and the Department of Medical Physics and Bioengineering for their help with the studies; and to Mrs. Grace Harris for preparing the manuscript.

\section{REFERENCES}

1. Cady EB, Costello AM deL, Dawson MJ, Delpy DT, Hope PL, Reynolds EOR, Tofts PS, Wilkie DR 1983 Non-invasive investigation of cerebral metabolism in newborn infants by phosphorus nuclear magnetic resonance spectroscopy. Lancet 1:1059-1062

2. Younkin DP Delivoria-Papadopolous M, Leonard J, Subramanian VH, Eleff S, Leigh JS, Chance B 1984 Unique aspects of human newborn cerebral metabolism evaluated with phosphorus nuclear magnetic resonance spectroscopy. Ann Neurol 16:581-586

3. Hope PL, Costello AM deL, Cady EB, Delpy DT, Tofts PS, Chu A, Hamilton PA, Reynolds EOR, Wilkie DR 1984 Cerebral energy metabolism studied with phosphorus NMR spectroscopy in normal and birth-asphyxiated in.. fants. Lancet 2:366-370

4. Hope PL, Reynolds EOR 1985 Investigation of cerebral energy metabolism in newborn infants by phosphorus magnetic resonance spectroscopy. Clin Perinatol 12:261-275

5. Hamilton PA, Hope PL, Cady EB, Delpy DT, Wyatt JS, Reynolds EOR 1986 Impaired energy metabolism in brains of newborn infants with increased cerebral echodensities. Lancet 1:1242-1246

6. Reynolds EOR, Wyatt JS, Azzopardi D, Delpy DT, Cady EB, Cope M, Wray S 1988 New non-invasive methods for assessing brain oxygenation and haemodynamics. Br Med Bull 44:1052-1075

7. Lawson B, Anday E, Guillet R, Wagerle LC, Chance B, Delivoria-Papadopolous M 1987 Brain oxidative phosphorylation following alteration in head position in preterm and term neonates. Pediatr Res 22:302-305

8. Dubowitz L, Dubowitz V, Goldberg C 1970 Clinical assessment of gestational age in the newborn infant. J Pediatr 77:1-10

9. Gairdner D, Pearson S 1971 A growth chart for premature and other infants. Arch Dis Child 46:783-787

10. Hope PL, Gould SJ, Howard S, Hamilton PA, Costello AM deL, Reynolds EOR 1988 Precision of ultrasound diagnosis of pathologically verified lesions in the brains of very preterm infants. Dev Med Child Neurol 30:457-471

11. Chu A, Delpy DT, Thalayasingam S 1986 A transport and life support system for newborn infants during NMR spectroscopy. In: Rolfe P (ed) Fetal and Neonatal Physiological Measurements. Butterworths, London, pp 409-415

12. Gordon RE, Hanley PE, Shaw D 1982 Topical magnetic resonance. Prog Nucl Mag Res Spectr 15:1-47

13. Petroff OAC, Prichard JW, Behar KL, Alger JR, den Hollander JA, Shulman RG 1985 Cerebral intracellular $\mathrm{pH}$ by $31 \mathrm{P}$ magnetic resonance spectroscopy. Neurology (NY) 35:781-788

14. Gadian DG 1982 Nuclear Magnetic Resonance and Its Application to Living Systems. Clarendon Press, Oxford

15. Tofts PS, Wray S 1985 Changes in brain phosphorus metabolites during the postnatal development of the rat. J Physiol (Lond) 359:417-429

16. Tofts PS, Wray S 1986 Non-invasive measurement of molar concentrations of $31 \mathrm{P}$ metabolites in vivo using surface coil NMR spectroscopy. Mag Res Med 
$6: 84-86$

17. Tofts PS 1986 Tissue localization in surface coil nuclear magnetic resonance (NMR) spectroscopy. In: Rolfe P (ed) Fetal and Neonatal Physiological Measurements. Butterworths, London, pp 363-372

18. Chance B, Leigh JS, Clark BJ, Maris J, Kent J, Smith D 1985 Control of oxidative metabolism and oxygen delivery in human skeletal muscle: a steady state analysis of the work/energy cost transfer function. Proc Natl Acad Sci USA 82:8384-8388

19. Larroche J-C 1977 Developmental Pathology of the Neonate. Exerpta Medica, Amsterdam, pp 320-353

20. Cady EB, Chu A, Costello AM deL, Delpy DT, Gardiner RM, Hope PL, Reynolds EOR 1987 Brain intracellular $\mathrm{pH}$ and metabolism during hypercapnia and hypocapnia in the new-born lamb. J Physiol (Lond) 382:1-14

21. Pettegrew JW, Kopp SJ, Dadok J, Minshew NJ, Feliksik JM, Glonek T, Cohen MM 1986 Chemical characterization of a prominent phosphomonoester resonance from mammalian brain: $31 \mathrm{P}$ and $1 \mathrm{H} \mathrm{NMR}$ analysis at 4.7 and 14.1 Tesla. J Mag Res 67:443-450

22. Bottomley PA, Hart HR, Edelstein WA, Schenk JF, Smitt LS, Lere WM, Mueller OM, Redington RW 1984 Anatomy and metabolism of the normal human brain studied by magnetic resonance at 1.5 tesla. Radiology 150:441446

23. Cerdan S, Subramanian VH, Hilberman M, Core J, Egan J, Chance B, Williamson JR 1986 31P NMR detection of mobile dog brain phospholipids. Mag Res Med 3:432-439

24. Gonzalez-Mendez R, Litt L, Koretzky AP, von Colditz J, Weiner W, James TL 1984 Comparison of 3IP NMR spectra of in vivo rat brain using convolution difference and saturation with a surface coil: source of the broad component in the brain spectrum. J Mag Res 57:526-533

25. Chang Y-C, Arus C, Barany M 1985 Characterization of the broad resonance in 31P NMR spectra of excised rat brain. Physiol Chem Phys 17:143-154

26. Kanashiro M, Naritomi H, Sasaki M, Sawada T, Tsuji S, Mivra R, Miyake Y 1986 Non-invasive 3IP NMR study on the development of myelin with gerbils and jimpy mice, a myelin-deficient mutant. Proceedings of the Society for Magnetic Resonance in Medicine, Fifth Annual Meeting, Montreal, pp 668-669

27. Hagberg B, Hagberg G, Olow I 1976 The changing panorama of cerebral palsy in Sweden 1954-1970: III: the importance of fetal deprivation of supply. Acta Paediatr Scand 65:403-408 